\title{
Aspectos subjetivos relacionados aos materiais e processos empregados na produção do livro impresso
}

Subjective aspects related to the materials and processes used in the production of the printed book

AMORIM, Wadson Gomes; Doutorando; Universidade do Estado de Minas Gerais (UEMG) wadsonamorim1@gmail.com

NERY, Cristiane; Doutoranda; Universidade do Estado de Minas Gerais (UEMG)

nery.cris@gmail.com

DIAS, Maria Regina Álvares Correia; Doutora; Universidade do Estado de Minas Gerais (UEMG)

regina.alvares@gmail.com

\section{Resumo}

Selecionar os materiais adequadamente para a produção dos produtos industriais sempre foi uma tarefa complexa para os designers, especialmente ligados ao design de produtos. O foco nesse estudo é o produto livro impresso, que agrupa características do design editorial e gráfico, mas com ênfase na seleção dos materiais e processo empregados na sua produção. No design de um livro, a ideia de provocar experiências positivas pode ser alcançada pelo seu próprio conteúdo, mas também a partir das escolhas formais e seleção de materiais. O método Permatus descrito no artigo, pode ser uma ferramenta útil para o designer avaliar os materiais, juntamente com os usuários, para obter respostas subjetivas de sua percepção dos materiais. Dessa maneira, o conhecimento sobre os aspectos sensoriais e simbólicos dos materiais em congruência com as suas características práticas pode oferecer informações flexíveis que possibilitem insights na criação de novos conceitos e inovação no design editorial.

Palavras chave: design editorial; materiais; livro impresso.

\begin{abstract}
Selecting materials appropriately for the production of industrial products has always been a complex task for designers, especially related to product design. The focus of this study is the printed book product, with editorial and graphic design features, but with an emphasis on the selection of the materials and process employed in its production. In the design of a book, the idea of provoking positive experiences can be achieved by its own content, but also from the formal choices and selection of materials. The Permatus Method described in the article can be a useful tool for the designer to evaluate the materials, along with the users, to obtain subjective answers of their perception of the materials. In this way, knowledge about the sensorial and symbolic aspects of materials in congruence with their practical characteristics can offer flexible information that allows insights in the creation of new concepts and innovation in editorial design.
\end{abstract}

Keywords: editorial design; materials; printed book. 


\section{Introdução}

O objeto livro, considerado aqui como resultado do design de produto e do design gráfico, incita sentidos e significados no usuário/leitor. Desse modo, a proposta deste trabalho é apresentar uma reflexão sobre como a análise subjetiva dos materiais empregados na produção dos livros pode contribuir para o campo do design editorial voltado para a experiência do usuário. Para tanto, é necessário, primeiramente, compreender que "autores não escrevem livros; eles escrevem textos. Os textos são moldados, transformados e interpretados por editores, designers e ilustradores." (MARTYN, 2011, p. 12)

Em se tratando da produção em massa do objeto livro, vale ressaltar que a escolha de formato, de papel e de preço normalmente é feita pelo editor. Já a produção independente aproxima o autor do designer, permitindo, assim, que ele participe das escolhas gráficas. De qualquer forma, para que o livro passe a "existir", é necessária a fabricação do papel e a composição tipográfica dos textos, os quais devem ser impressos e encadernados. É válido lembrar que, antigamente, esses textos eram copiados à mão por escribas, o que tornava a produção menos comercial. Atualmente, a publicidade e o marketing criam estratégias comerciais voltadas para públicos específicos, de modo que existe toda uma cadeia de armazenagem e distribuição que faz com que o produto livro seja levado até os pontos de venda ou diretamente ao consumidor final. Nesse cenário, o autor, "é, na verdade, apenas um dos elementos de uma complicada cadeia produtiva." (MARTYN, 2011, p. 12)

Sem dúvida, o livro tornou-se uma tecnologia útil, versátil e duradoura. De acordo com Martyn (2011), ele tornou-se indispensável pela sua capacidade de armazenar dados e conhecimentos, por ser portátil e de fácil reprodução, podendo ser distribuído em qualquer língua e lugar. O livro foi uma importante ferramenta em alguns momentos da história ocidental, como durante o Renascimento, a Reforma, a Revolução Científica, o lluminismo, uma vez que nessas ocasiões, "valeram-se todos da palavra impressa para sua difusão e influência permanentes. Durante dois milênios e meio, a humanidade usou o livro, na sua forma manuscrita ou impressa, para registrar, administrar, venerar e educar." (MARTYN, 2011, p. 7)

Dessa forma, é importante considerar o leitor como elemento fundamental desse processo. Assim, se o livro for entendido como uma "interface" que possibilita o leitor-usuário de acessar determinado conhecimento, quanto mais pertinente for essa interface, melhor. E essa pertinência, no caso do livro, pode ser potencializada pela escolha e seleção dos materiais.

A seleção e a escolha dos materiais acontecem mediante os diversos tipos de processos de produção existentes e a relação desses com o conteúdo que o livro pretende transmitir. Desde a definição da tipografia, do grid, da capa, da diagramação até a determinação do tipo de impressão, de papel e do acabamento, todas as decisões formais estarão voltadas para que a mensagem do livro possa ser transmitida da melhor maneira possível para o leitor/usuário. "O design do livro é uma arte que tem suas próprias tradições e um corpo relativamente pequeno de regras aceitas." (HENDEL, 2006, p. 1). De acordo com Samara (2011, p. 13), durante o processo de produção do livro "o papel do designer é examinar o conteúdo e começar a pensar em sua aparência e sensação, em relação às suas mensagens." Sobre o conteúdo, Rand (2010) afirma o seguinte:

O conteúdo é basicamente a ideia, é isso que é o conteúdo. Forma é como você trata a ideia, o que você faz com ela. Este é exatamente o significado do design: o conflito entre forma e conteúdo, sendo a forma o problema. Ou seja, é como você faz, como você mostra 
algo, como você pensa, como fala, como dança; a coreografia é o conteúdo. [...] Por um lado, isso não é simples, mas, por outro, é. O casamento da forma com o conteúdo é a realização do design (RAND, 2010 In: KROEGER, 2010, p. 46-47).

De acordo com Karana (2009), os materiais selecionados para o desenvolvimento de produtos não afetam somente seu uso e sua função, mas também contribuem para criar significados e suscitar emoções nos usuários. Dessa forma, atributos podem ser utilizados para avaliar os significados subjetivos do uso dos materiais empregados na produção dos livros e os sentidos e significados provocados no usuário/leitor.

Para tanto, serão investigados, nessa proposta, quatro elementos fundamentais para a interação entre o usuário e o livro impresso: a impressão, o papel, o layout e o acabamento. Posteriormente, será apresentada a possibilidade de utilização do Modelo Permatus (Percepção dos Materiais pelos Usuários) para a avaliação subjetiva do design de livros, voltada para a abordagem de seus materiais. O Modelo Permatus "é parte de uma pesquisa que teve como objetivo estudar como os usuários percebem significados dos materiais presentes nos produtos de seu cotidiano, conforme relatado em Dias (2009)." (DIAS, 2011, pág. 5)

\section{Etapas de produção de um impresso e os elementos do livro}

As quatro grandes etapas de produção de um impresso estabelecidas por Villas-Boas (2010, p. 16-17), tendo como referência o processo offset, o qual será mais detalhado a seguir, são: projetação; pré-impressão e impressão; acabamento. É importante ressaltar que a produção de um livro passa por essas quatro etapas e, em cada uma delas, define-se como o conteúdo do livro será transformado em produto e apresentado para o seu usuário final ou consumidor. Para tanto, cada etapa possui tarefas bem definidas, conforme se pode observar no quadro a seguir:

Quadro 1 - Etapas na produção do livro impresso

\begin{tabular}{lll}
\hline ETAPA & LOCAL DE REALIZAÇÃo & TAREFAS \\
\hline PROJETAÇÃO & Escritório & Projeto gráfico; diagramação e/ou layout; arte-finalização. \\
\hline PRÉ-IMPRESSÃO & Birô & $\begin{array}{l}\text { Digitalização de imagens*; edição de imagens*; Provas de } \\
\text { alta resolução para o cliente*; Geração de fotolitos*; } \\
\text { Revelação dos fotolitos*; Provas dos fotolitos*. }\end{array}$ \\
\hline IMPRESSÃO & Gráfica & $\begin{array}{l}\text { Montagem da matriz e imposição de páginas; gravação das } \\
\text { matrizes; revelação das matrizes*; prova de chapas (ou das } \\
\text { matrizes) *; Provas de contrato*; impressão. }\end{array}$ \\
\hline ACABAMENTO & Gráfica ou terceiros & $\begin{array}{l}\text { Dobras*; revestimentos*; vernizes*; relevos*; refiles; } \\
\text { cortes especiais e outros*; encadernação*; } \\
\text { empacotamento. }\end{array}$ \\
\hline
\end{tabular}

Fonte: adaptado de Villas-Boas, 2010, p. 16-17

As etapas que estão marcadas com (*) poderão ou não acontecer de acordo com o projeto a ser desenvolvido. 
A partir dessa divisão, foram elencados, para este estudo, os seguintes elementos do livro: layout; impressão, papel, acabamento. Esses elementos influenciam diretamente o leitor, tanto no momento da escolha e compra do produto, quanto durante a leitura e o manuseio do livro. É uma relação estabelecida pelas sensações causadas pelo visual e pelo acabamento gráfico.

\title{
2.1 O Layout
}

De acordo com Corallo (2007), layout é a "configuração gráfica dos elementos de grafismo e contra-grafismo que compõe uma peça visual impressa". A respeito dessa configuração, Haslam (2010, p. 140) explica que "o processo de execução do layout de um livro envolve o trabalho de designers que tem que tomar decisões sobre o posicionamento exato de todos os elementos da página".

\begin{abstract}
Quando vamos à uma livraria, fazemos uma "leitura prévia" dos livros que nos interessam, folheando suas páginas e fazendo julgamentos instintivos sobre o conteúdo, qualidade e apelo geral. Nossa primeira impressão pode estar ligada ao uso do espaço, à cor ou a composição das obras. Tais notas comunicam subliminarmente um conjunto de valores sobre a página e, por conseguinte, sobre o texto, além de por associação revelarem aspectos do autor. Se o layout da publicação for desmazelado, a impressão/acabamento de má qualidade e uso do espaço inadequado, então o texto, não importando quão eloquente seja, será inevitavelmente desvalorizado. Se a primeira impressão de uma página dupla espelhada, por exemplo, encher o leitor de confiança - passando-Ihe uma sensação de ordenamento, de construção bem-definida ou mesmo de desconexão deliberada do layout - a pré-leitura desse código semiótico poderá valorizar o texto. (HASLAM, 2010, p. 140).
\end{abstract}

Haslam (2010) explora diversos elementos do livro: formato; grades (grid); paleta tipográfica; tipo; estrutura editorial; imagens; layout; capas e sobrecapas. Todos esses elementos podem ser avaliados por atributos que permitem identificar a reação subjetiva do usuário/leitor.

\subsection{A impressão}

A impressão, de acordo com Villas-Boas (2010, p.15), é um "processo de transferência de pigmentos de uma matriz para um suporte visando à obtenção de cópias."

Os pigmentos podem ser aglutinados em forma líquida ou pastosa, ou em pó, em gelatina etc. e este veículo pode ser denominado tinta, toner, fita ou filme. O suporte pode ser tanto papel quanto plástico, madeira, metal, tecido etc. [...]. As cópias podem ser em quantidades diversas, de dezenas a milhares ou mesmo apenas uma (mas, no ambiente industrial, o processo só é inadequado se só for capaz de produzir uma única cópia). (VILLAS-BOAS, 2010, p. 15)

Os processos de impressão correspondem às diversas maneiras de realizar esse processo de transferência. Assim, cada técnica empregada irá transmitir uma sensação, uma ideia, um conceito ao público final. Um livro impresso com xilogravura, por exemplo, causa uma emoção e uma sensação diferente no leitor quando comparado a um livro impresso em Offset. Nesse sentido, o manuseio é diferente, o olhar é diferente, a relação entre o usuário e o produto é outra. Além disso, as escolhas de materiais devem ser realizadas de acordo com o conteúdo do livro e seus meios de circulação.

Liu (2013) identifica e descreve desde os processos de reprodução industriais até os processos de impressão artísticos artesanais: Rotogravura; Offset; Flexografia; Serigrafia Rotativa; Laser; Tampografia; Estampagem; Metalgrafia; Xilogravura; Linogravura; Serigrafia; Thermofax; Gravura Metal; Litografia; Cromolitografia; Tipografia; Mimeografia; Termografia; Matricial; Braille; 
Fax; Térmica; Jato de tinta; Risograph; Datilografia; Monotipia; Hectografia; Carimbo; Letraset; Transfer; Estêncil; Marmorização.

Villas-Boas (2010) explica que o processo mais utilizado pelos designers é o Offset. Essa técnica surgiu na segunda metade do século XX e é caracterizada por ser um processo indireto, uma vez que utiliza matrizes a partir de chapas de alumínio que servem como meio de gravação e transferência da imagem para o substrato (suporte). Nesse método de impressão, as cores CMYK são impressas uma a uma e formam as imagens por adição da pigmentação das cores.

\begin{abstract}
A impressão offset é o processo mais utilizado na impressão comercial. Além disso, a impressão offset é o padrão mais utilizado na indústria gráfica pela capacidade de imprimir em alta qualidade, conferindo ao produto final uma apresentação superior. A impressão offset é um processo que consiste da interação entre água e gordura (a tinta offset é de consistência gordurosa). O processo de impressão offset é indireto, ou seja, a imagem é transferida da matriz para um rolo de impressão (blanqueta) e somente depois é passada ao papel. Por isso a matriz (chapa offset) é legível mesmo antes da impressão, diferentemente dos processos diretos onde a matriz é espelhada (textos escritos invertidos) $)^{1}$
\end{abstract}

\title{
2.3 O papel
}

Segundo o ABC DA ADG (1998, p. 82, apud LIU, 2013, p.135), o papel é um "material constituído por elementos fibrosos de origem vegetal e cola que, reduzidos a uma pasta de celulose, que se faz secar e refinar sob forma de folhas delgadas, utilizadas para escrita, desenho, impressão e outros fins."

A indústria de papel se desenvolve rapidamente, lançando novidades constantes no mercado. No entanto, Ambrose e Harris (2009, p. 12) definem apenas dez tipos de papel que podem ser "impressos com um dos processos de impressão convencionais." São eles: papel-jornal; papel antique; papel não revestido; pasta mecânica; papel cartão-supremo; papel couché; papel couché monolúcido de alto brilho; papel cromo; papel cartão de alta qualidade; papel cartão de fibra reciclada.

Já Liu (2013) cria uma lista ilustrada com 60 diferentes papeis que podem servir como suporte para algum tipo de método de impressão: Bíblia; Papel Algodão; Jornal; Offset; Couché; Cartão; Kraft; Paraná; Couro; Papelão Cinza; Papelão; Papelão Ondulado; Polpa Moldada; Espelho; Metalizado; Calandrado; Flocado; Estampado; Marmorizado; Holográfico; Yupo; Tyvek; Mylar; Crepom; Seda; Manilha; Monolúcido; Frezzer; Papel Parafinado; Alumínio; Comestível; Espuma; Adesivo; Celofane; Vegetal; Manteiga; Reciclado; Xuan; Washi; Artesanal; Machê; Colorido; Estéril; Carbono; Autocopiativo; Termossensível; Fotográfico; Bolha; Água; Prova D'água; Transfer; Laminado; Filigranado; Papel Filtro; Guardanapo; Higiênico; Segurança; Magnético; Luminescente; Abrasivo.

Em se tratando da constituição física do papel, Haslam (2010, p. 191) afirma que o papel "tem sete características-chave: o formato, a gramatura, o corpo, o sentido da fibra, a opacidade, o acabamento e a cor".

No entanto, Baer (1999) separa as características do papel em físicas; mecânicas; de superfície; químicas e funcionais. As características físicas são: gramatura; rigidez da folha; grau de absorção da folha; grau de colagem; aspereza superficial; porosidade da folha; acabamento. As

\footnotetext{
${ }^{1}$ Impressão Offset. Disponível em: <http://www.expoprint.com.br/pt/impressao-offset> Acesso em: 25 jun. 2017.
} 
características mecânicas são: resistência do papel à tração; resistência ao estouro (arrebentamento); resistência ao rasgo; resistência a dobras duplas. A característica de superfície corresponde ao revestimento do papel. As características químicas são: pH do papel; cinza do papel; propriedades ópticas; cor; opacidade e brilho. E, por fim, as características funcionais são: absorção da tinta; imprimibilidade; arranchamento superficial (pick); pulverulência superficial (fluff); resistência à água de umedecimento; estabilidade dimensional.

Em relação à escolha do papel, Villas-Boas (2010) define quatro critérios que devem ser adotados, a saber, o valor subjetivo; o custo; a disponibilidade no mercado e as restrições técnicas. Seguindo esses parâmetros, Villas-Boas (2010) também define algumas propriedades que devem ser levadas em consideração para a seleção do papel mais adequado ao projeto, que são: formação da pasta; revestimento; gramatura; espessura; opacidade; grau de colagem; lisura e textura; alcalinidade ( $\mathrm{pH}$ superficial); alvura e cor, direção das fibras; e formato de fábrica.

É importante ressaltar que cada uma das características apresentadas anteriormente pode ser avaliada em relação ao modo como o usuário irá reagir ao manusear o livro.

\section{4 acabamento}

Villas-Boas (2010, p. 158) explica que o "acabamento possui algumas operações básicas (refile, dobraduras, encadernação) e outras específicas". O autor descreve detalhadamente os seguintes acabamentos: refile; dobradura; vincagem; cortes (com uso de faca); encadernação (canoa, lombada quadrada, com costura e cola, com tela, mecânica); capas (capa brochura, capa dura e capa flexível); impressões adicionais (gravação a quente - hot stamping, timbragem, relevo americano); revestimentos (plastificação, laminação, verniz); vernizes (verniz de máquina, verniz de alto brilho, verniz UV.); efeitos sobre o papel (impressão em relevo, relevo seco, gofragem, serrilhados, picotes).

Outros recursos descritos pelo autor são: douração do corte; encartes; vacum-forming; solda eletrônica e, ainda, o empacotamento.

É válido mencionar que cada um desses acabamentos transmite uma sensação diferente para o leitor. Desse modo, a avaliação de todos esses materiais apresentados pode levar a uma melhor seleção daqueles que serão empregados em um projeto. Os atributos desses materiais podem ser ensinados aos designers dentro das disciplinas específicas nos cursos para que a avaliação subjetiva da relação entre o leitor e o livro possa ser mais bem explorada, como já é feita com outros diversos produtos

\section{Seleção de materiais no campo do design}

Uma das competências esperadas do designer é conhecer sobre os materiais, bem como sobre as técnicas, tecnologias e modos de fabrico, de produção e das ciências correspondentes. A partir desse conhecimento específico, podem-se materializar os conceitos em um artefato. Porém, percebe-se atualmente uma ênfase excessiva nas propriedades tangíveis do produto, baseada, quase exclusivamente, em formas e propriedades físicas. Como defende Dias (2009), a concepção, a seleção e a utilização de materiais, em cada uma das dimensões do desenvolvimento de um produto, requer o atendimento de pressupostos de ordem tanto objetiva quanto subjetiva. Assim, a utilização de materiais em um livro impresso pressupõe um conjunto de conhecimentos necessários que também estão atrelados a questões intangíveis. Nesse sentido, a amplitude das relações possíveis entre o usuário e o livro evidencia a necessidade de se pensar o material a partir de suas propriedades físicas sem descartar 
a sua capacidade de desencadear reações subjetivas sensório-cognitivas.

Atualmente, existem ferramentas utilizáveis nos processos de seleção de materiais. Porém, a maioria dessas ferramentas é baseada na engenharia, dominadas por dados numéricos ou técnicos. Essas ferramentas avaliam, através de softwares específicos, aspectos como a racionalização e aproveitamento do suporte ou a homogeneidade da sua impressão, que são principalmente de uso nas fases de desenvolvimento e produção física de novos produtos. Assim, há um campo a ser explorado: ferramentas e discussões sobre o projeto de propriedades intangíveis dos materiais empregados no livro impresso.

Por outro lado, os designers contemporâneos consideram importante certos aspectos, como a personalidade do livro, a interação do usuário, os significados, as emoções em suas decisões materiais, haja vista a pluralidade de ofertas encontradas no mercado atualmente, principalmente no que diz respeito aos formatos, layouts e suportes utilizados. Porém, é possível potencializar ainda mais o processo de seleção de materiais valendo-se das ferramentas e os métodos dessa área.

De fato, a compreensão da subjetividade na relação homem-material é algo complexo. Os designers que pretendem criar certos significados através dos materiais de seus produtos são confrontados com a dificuldade de não haver uma relação um-para-um entre as propriedades dos materiais e os significados pretendidos (KARANA, 2009). Desse modo, projetar combinações de diferentes propriedades que evocam significados particulares para contextos e usuários específicos pode ser uma tarefa árdua.

É importante ressaltar que o repertório individual de designers e usuários interfere na percepção dos materiais. A partir dessa constatação, as novas ferramentas como o MoM - Meanings of Materials (KARANA, 2009) e o Permatus - Percepção dos materiais pelos usuários (DIAS, 2009) emergem como grandes contribuições para o campo. Esses modelos de significados têm em comum o objetivo de transmitir as descobertas sobre os atributos subjetivos dos materiais aos designers, de tal forma que eles suportem e aprimorem suas atividades de criação de significado através da seleção de materiais. Entretanto, os enfoques dessas ferramentas estão no design de produtos em geral, mas a proposta aqui é que também possa ser aplicado em objetos específicos do campo do design gráfico, como um livro.

Aos poucos, o conhecimento sobre as propriedades intangíveis dos materiais está perdendo o empirismo e permitindo que elas sejam projetadas de maneira justificada. Hoje em dia, com as possibilidades abertas pela inovação técnica, o designer tem que se orientar entre numerosas opções, adaptar a sua capacidade intuitiva, a sua criatividade e o seu método de trabalho à tendência geral para a abstração, à imaterialidade e à multiplicidade de parâmetros que deve equacionar para trabalhar com a matéria (DIAS, 2009). Assim, a capacidade criativa do designer deve estar instrumentalizada por um conhecimento mais profundo dos materiais no plano da experiência.

Chapman (2005) afirma que, como disciplina, o design de experiência é um campo que foi formalmente reconhecido e nomeado muito recentemente. No atual mercado, cada vez mais orientado para a experiência, é fácil entender como esta nova e experimental área tem um papel fundamental a desempenhar. Como área de prática criativa, o design de experiência pode ser descrito como uma síntese de disciplinas do design contemporâneo que, quando entrelaçadas, facilitam a geração de soluções criativas para uma ampla gama dos problemas atuais. Nesse sentido, um de seus pontos fortes é sua natureza interdisciplinar. De acordo com o American Institute of 
Graphic Arts (AIGA), o design de experiência é uma abordagem com limites mais amplos do que o design tradicional, e que se esforça para criar experiências além de produtos ou serviços. Trata-se de um processo qualitativo, que abrange o planejamento, a pesquisa, a conceituação, a concepção e o desenvolvimento de objetos e experiências.

Como visto nos tópicos anteriores, a produção de impressões envolve uma variedade de materiais e processos. Em razão disso, é preciso considerar que as escolhas entre as possibilidades permitem provocar experiências específicas no usuário ao se relacionar com o objeto. Desse modo, ampliar essa compreensão é permitir ao designer aproveitar ao máximo os recursos disponíveis para criar projetos inovadores, excitantes e duradouros. Chapman (2005) parte do pressuposto de que atualmente vivemos em um mundo insustentável dos bens, no qual os produtos são desejados, comprados, usados brevemente e rapidamente descartados. Entendendo que as relações entre os consumidores e os produtos são de curta duração e pouco estimulantes atualmente, o autor propõe o surgimento de um novo gênero que reduza o consumo e o desperdício, aumentando a durabilidade a partir das relações afetivas e emocionais estabelecidas entre usuários e produtos.

Como já foi abordado, no design de um livro, a ideia de provocar experiências positivas pode ser alcançada a partir das escolhas formais e da seleção de materiais. De acordo com Dias (2009, pág. 136), o "perfil subjetivo de um material é definido pelas características intangíveis, ou seja, os significados atribuídos e as emoções evocadas, que não podem ser puramente identificadas com valores numéricos ou quantificadas." A autora identifica e define 58 atributos subjetivos dos materiais que podem ser utilizados na análise de produtos, os quais estão "organizados em atributos estéticos, práticos, simbólicos e outras influências" (DIAS, 2009, p. 14), conforme mostrado na figura a seguir:

Figura 1 - Quadro dos possíveis atributos subjetivos que se relacionam aos materiais do produto a ser avaliado.

\begin{tabular}{|c|c|c|c|}
\hline ESTÉTICOS & PRÁTICOS & SIMBÓLICOS & PERFIL E COMPORTAMENTO \\
\hline A1- FORMA & A13- IDENTIFICAÇĀO & A29- CULTURA E TRADIÇÃO & A48- CONTEXTO GEOGRÁFICO \\
\hline A2- $\mathrm{COR}$ & A14- USABILIDADE & A31- ENVELHECIMENTO & A49- GÊNERO \\
\hline A3- TRANSPARÊNCIA & A15- ERGONOMIA & A32- NATURAL E ARTIFICIAL & A50- IDADE \\
\hline A4- BRILHO & A17- CONTEXTO DE USO & A33- AUTÊNTICO E IMITAÇĀO & A51- PROFISSÃO \\
\hline A5- TÁTIL E HÁPTICA & A18- CONFORTO & A34- ARTESANAL E INDUSTRIAL & A52- EXPERIÊNCIA \\
\hline A6- TEXTURA & A19- SEGURANÇA E PROTEÇĀO & A35- INOVAÇÃO & A53- ESTILO DE VIDA \\
\hline A7- SOM & A20- LIMPEZA E HIGIENE & A36- IDENTIDADE & A54- BARATO-LUXO \\
\hline A8- CHEIR0 & A21- SAÚDE E SALUBRIDADE & A37- VALOR DE MARCA & A55- TENDÊNCIAS \\
\hline A9- SABOR & A22- SUSTENTABILIDADE & A38- VALOR DA IMAGEM & A58- BENEFÍCIOS \\
\hline A10- TEMPERATURA & A23- QUALIDADE & A39- PREÇO & \\
\hline A11- PROP. FÍSICA E MECÂNICA & A25- CONFIABILIDADE & A40- VALOR SOCIAL & \\
\hline \multirow[t]{5}{*}{ A12- EXPRESSÃO PELO PROCESSO } & A26- RESISTÊNCIA & A41- VALOR SENTIMENTAL & \\
\hline & A27- EFICIÊNCIA ENERGÉTICA & A44- ASSOCIAÇÃO & \\
\hline & A28- DURABILIDADE & A45- PADRÕES & \\
\hline & & A46- ESTILO DE DESIGN & \\
\hline & & A47- PERSONALIDADE & \\
\hline
\end{tabular}

Fonte: (Dias, 2009, p. 175)

Esses atributos apresentados pela autora podem ser utilizados na análise e na seleção de materiais utilizados na produção de livros impressos. 
O livro, em sua totalidade, bem como seus elementos, já apresentados anteriormente Layout; Impressão; Papel e Acabamento - podem ser avaliados de acordo com o Modelo Permatus, cuja arquitetura básica está apresentada sinteticamente na figura a seguir.

Figura 1 - Quadro do resumo do Modelo Permatus com objetivos, participação, procedimentos e resultados de cada etapa de análise

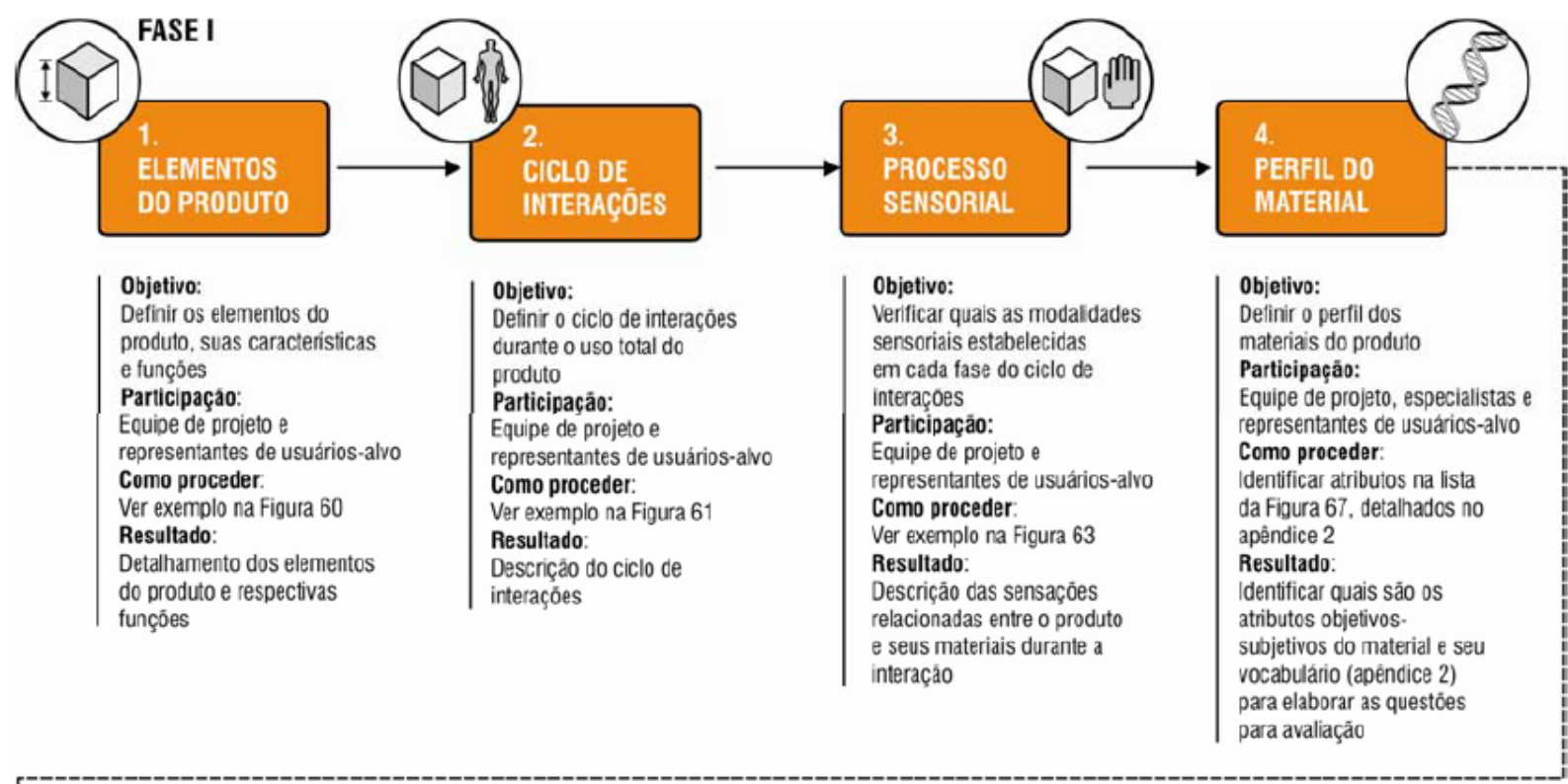

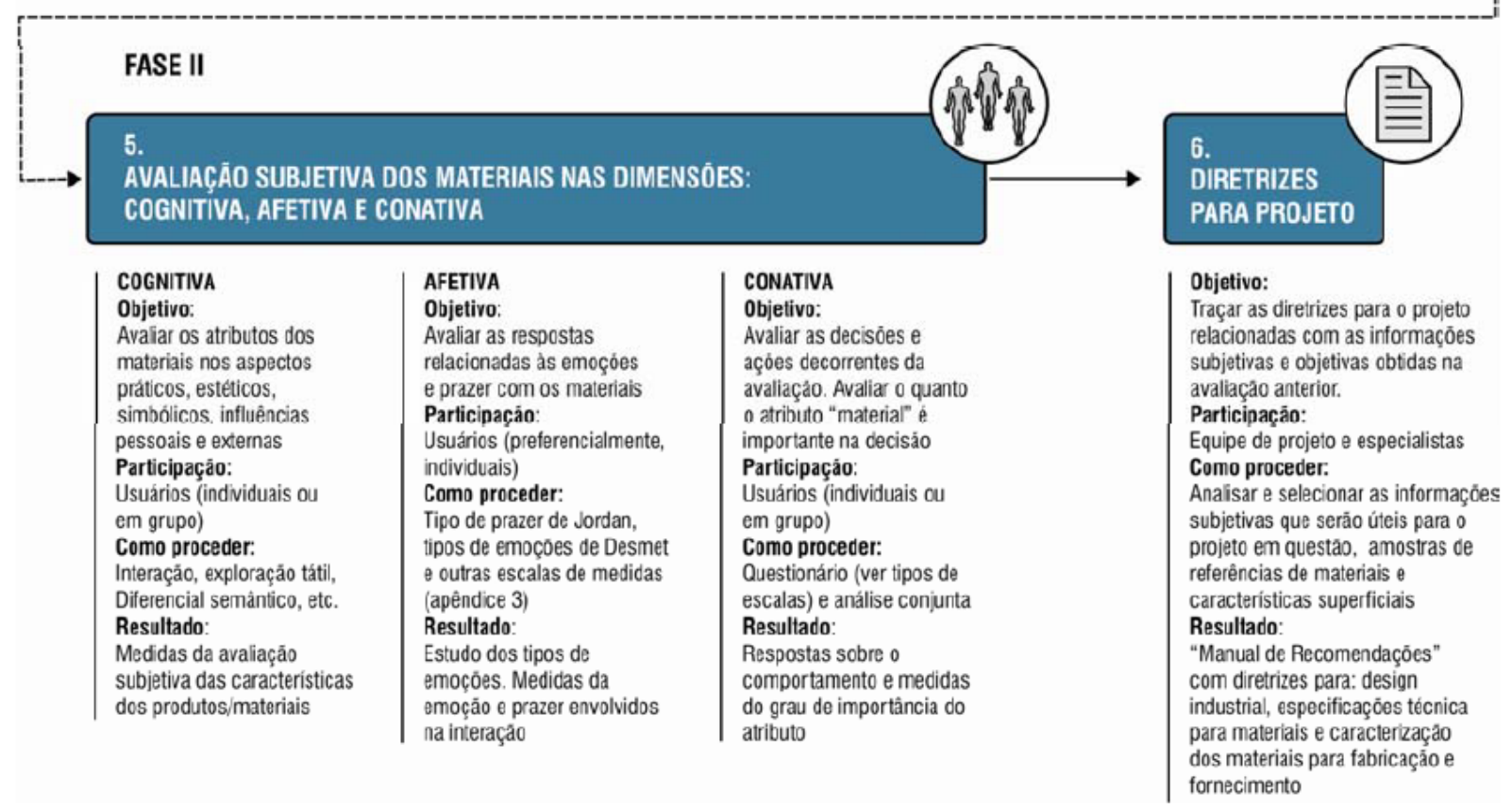

Fonte: (Dias, 2009, p. 151)

A aplicação do modelo Permatus pode se dar no início do processo de design gráfico do livro, quanto para avaliar produtos antes produzidos, como forma de também verificar se o produto ou uma coleção de livros pode ser melhorada para atingir melhor seus usuários. 
Alguns exemplos práticos podem facilitar a compreensão desta aplicação: no caso de um livro para o público infantil o designer poderá selecionar os materiais, seja da capa e miolo, mais adequados levando em conta os atributos estéticos listados na Figura 1, como a cor, o brilho e a textura tátil do papel, da tinta ou do acabamento. Pode-se, inclusive avaliar se outras modalidades sensoriais podem ser valorizadas para o público infantil desejado e inserir som, cheiro ou até sabor ao material. São possibilidades tecnicamente possíveis de se empregar desde que traga significado ao produto. Outros atributos práticos e simbólicos pode ser relevantes para o mesmo público, como a ergonomia e segurança relacionados ao material do livro. A natureza do papel, com variações de espessura e peso, pode apresentar risco e perigo para as crianças, o formato, a borda podem machucar a pele sensível das crianças. As tintas e acabamentos devem ser isentas de substâncias nocivas à saúde que possam causar alergias às crianças. Alguns tipos de materiais para os livros podem até se expandir além da matéria-prima do papel - o plástico, elastômero, tecido são exemplos de materiais que possuem características interessantes para contextos de uso do livro infantil, como a propriedade de resistência a água dos plásticos ou do conforto tátil e conformo dos tecidos.

\section{Considerações finais}

A utilização adequada das propriedades dos materiais, tanto do ponto de vista de seu perfil técnico (objetivo), quanto do perfil sensório-cognitivo (subjetivo), permite o desenvolvimento de ferramentas que poderão estimular designers em formação a interpretar e produzir a partir dessa complexidade. O conhecimento sobre os aspectos sensoriais e perceptivos dos materiais em congruência com as suas características práticas pode oferecer informações flexíveis que possibilitem insights na criação de novos conceitos para inovação no design editorial.

Nesse sentido, a aplicação do Modelo Permatus para uma análise subjetiva dos materiais empregados na produção dos livros impressos pode contribuir para o campo do design editorial voltado para a experiência do usuário. Além disso, pode contribuir para a prática do ensino do design, capacitando alunos de design gráfico e editorial para uma nova relação com os materiais utilizados nesse campo, visto que permite uma compreensão melhor do modo como os usuários percebem significados dos materiais utilizados na produção gráfica de livros. 


\section{Referências}

AMBROSE, Gavin; HARRIS, Paul. Impressão e acabamento. Porto Alegre: Bookman, 2009.

BAER, Lorenzo. Produção gráfica. São Paulo: Editora Senac São Paulo, 1999.

CHAPMAN, Jonathan. Authors of experience. In: Emotionally durable design: objects, experiences and empathy. Londres: Earthscan, 2005.

CORALLO, Antônio Celso. Produção Gráfica: arte e técnica da mídia impressa. São Paulo: Pearson Prentice Hall, 2007.

DIAS, Maria Regina Álvares Correia. Percepção dos materiais pelos usuários: modelo de avaliação Permatus. Florianópolis, 2009, 352f. Tese (Doutorado em Engenharia e Gestão do Conhecimento), Universidade Federal de Santa Catarina - UFSC, Florianópolis, 2009.

DIAS, Maria Regina Álvares Correia; GONTIJO, Leila Amaral. Método Permatus para a seleção de materiais. In: Anais do XXXI ENCONTRO NACIONAL DE ENGENHARIA DE PRODUCAO Inovação Tecnológica e Propriedade Intelectual: Desafios da Engenharia de Produção na Consolidação do Brasil no Cenário Econômico Mundial Belo Horizonte, MG, Brasil, 04 a 07 de outubro de 2011. Disponível em: <http://www.abepro.org.br/biblioteca/enegep2011_tn_sto_139_882_18117.pdf> Acesso: 29 jul. 2017.

HASLAM, Andrew. O livro e o designer II: como criar e produzir livros. Tradução de Juliana A. Saad. São Paulo: Rosari, 2007.

HENDEL, Richard. O design do livro. Trad. Geraldo Gerson de Souza e Lúcio Manfredi. São Paulo: Ateliê Editorial, 2006.

LIU, Eunice. Design gráfico: processo como forma. Dissertação (Mestrado em Arquitetura e Urbanismo) Faculdade de Arquitetura e Urbanismo da Universidade de São Paulo, São Paulo, 2013.

MARTYN, Lyons. Livro: uma história viva. São Paulo: Editora Senac São Paulo, 2011.

KARANA, Elvin. Meanings of materials. 2009, 272f. Tese (Doutorado em Industrial Design). Delft: Delft University of Technology, 2009.

KROEGER, Michael (Org.). Conversas com Paul-Rand. Textos Philip Burton et al. Tradução de Cristina Fino. São Paulo: Cosac \& Naify, 2010.

SAMARA, Timothy. Guia de design editorial. Porto Alegre: Bookman, 2011.

VILLAS-BOAS, André. Produção gráfica para designers. Rio de janeiro: 2AB, 2010. 